\title{
Integrating palliative medicine in oncology care: the Hong Kong experience
}

Palliative care is an essential component of oncology service. The specialty of palliative care has advanced from a humble beginning in 1960s with focus at end-of-life care (1), to nowadays multidisciplinary service with integration in routine oncology care (2). High level of evidence has proven the benefit of early palliative care provision to cancer patients $(3,4)$, whereas the exact role of oncologists in the integrative service is still evolving (5-7).

In Hong Kong, palliative care service for cancer patients is provided by both palliative care physicians and clinical oncologists. The service was first initiated in 1967 when Nam Long Hospital was established by Hong Kong Anti-Cancer Society led by renowned clinical oncologist Prof. John HC Ho (8). In 1982, the first palliative care team was established in Our lady of Maryknoll Hospital. Thereafter, more palliative care teams were established, and the service was then incorporated into Hospital Authority under public funding in 1990s. In early years palliative care services were mainly under the care of specialists of internal medicine. Palliative medicine was established as a specialty under the Hong Kong College of Physicians in 1998 (9).

At the same time, cancer service in public cancer centers of Hospital Authority expanded quickly in 1990s. Hong Kong followed the clinical oncology service model of UK that clinical oncology provided comprehensive service including radiation therapy and systemic therapies. There was also elevating needs on palliative care for late-stage patients. In response to the service need, clinical oncology departments of Hospital Authority developed palliative care teams within oncology service (10). Designated palliative care beds were set up in oncology wards for symptom control and end-of-life care. Palliative care clinics were established to facilitate early initiation of ambulatory patients. Multidisciplinary palliative care teams and home care nursing teams were also set up to provide holistic care for advanced cancer patients. Three of the public oncology centers of Hong Kong received accreditation of European Society Medical Oncology (ESMO) as designated centers of integrated oncology and palliative care in 2008.

Besides service advancement, palliative care training program and subspecialty system were set up (10). Palliative medicine was formally founded as a subspecialty under clinical oncology in 2002. This was a post-fellowship training opened for voluntary enrollment of resident trainees who had completed intermediate oncology examinations. Trainees needed to undergo 4-year training in palliative medicine and higher oncology program. Upon completion of didactic sessions, trainees needed to submit case portfolios, audit report and a thesis before taking the board examination.

This series was the collective work of the trainees in the class 2015 to 2019. The diversity of projects represents the wide spectrum of clinical service of clinical oncologists in Hong Kong — on one hand oncologists need to make decisions on the use of advanced anticancer therapies like stereotactic body radiation therapy (SBRT) and immunotherapy, mostly for palliative cancer patients; on the other hand they also need to take care of palliative care interventions and end-of-life issues.

In the first session, studies reviewed how advanced anticancer treatments impacted on management of palliative cancer patients. Ho et al. (article 1) analyzed local data of 754 patients to look for predictors of early mortality within 6 weeks of systemic treatment initiation. The finding aided oncologists to exercise caution in patients with advanced age and active liver metastases. Lau et al. (article 2) reviewed local real-world data on the use of immune-check point immunotherapy in metastatic cancer patients. It was noteworthy the use of immunotherapies might affect patients' transition to hospice care that only $24 \%$ received this necessary care before pass away. Chik (article 3) and Yeung (article 4) evaluated the use of advanced RT technique for spinal and ocular tumors.

In the second session, hospice and end-of-life care in oncology departments were examined. Cheung et al. (article 5) reported a cohort of ketamine use in 70 patients with refractory pain. The outcome was encouraging that there was near $75 \%$ of favorable response with considerable decrease of concurrent morphine dose. Chan et al. (article 6) described the use of abdominal drain for repeated drainage and the management of its possible infectious complications. Tin et al. (article 7) analyzed a cohort of 339 days of end-of-life care in 180 patients. The use of low dose midazolam at 10mg over 24 hours, a lower dose compared with western cohort, achieved satisfactory level of symptom control without evidence of shortening of patients' survival. 
While clinical oncology teams in Hong Kong had gained considerable experience in end-of-life care, we had the opportunity to share our model with colleagues in mainland China. Shenzhen, a metropolitan area in Southern China, set up a comprehensive public hospital with acute palliative service in oncology ward. Li et al. (article 8) reported the end-of-life care of 441 cancer patients under the mainland health system. High level of DNA-CPR acceptance was an encouraging sign of the success of Hong Kong model.

In the last session, the future development of palliative care in Hong Kong was discussed based on two survey studies by Ms Hsue et al. (article 9) and Yeung et al. (article 10). The reports indicated the need of further public education on the principle and benefit of palliative care. The need of home death, as well as its barriers and facilitating factors, were discussed.

In the past 2 decades clinical oncologists in Hong Kong had gradually built up the palliative care capacity with integration into routine service. The manuscript published in the current issue concluded our initial works which will serve as a basis for service enhancement in future. Last but not least, we would like to express our gratitude to the multidisciplinary palliative care teams for all the achievements, as well as the patients and their families for their trust in us.

\section{Acknowledgments}

We would like to acknowledge the trainers and examiners of palliative care subspecialty board of the Hong Kong College of Radiologists.

Funding: None.

\section{Footnote}

Provenance and Peer Review: This article was commissioned by the editorial office, Annals of Palliative Medicine for the series "Integrating Palliative Medicine in Oncology Care: The Hong Kong Experience". The article did not undergo external peer review.

Conflicts of Interest: Both authors have completed the ICMJE uniform disclosure form (available at http://dx.doi.org/10.21037/ apm-2018-ipco-11). The series "Integration of Palliative Care into Oncology" was commissioned by the editorial office without any funding or sponsorship. MWRY served as the unpaid Guest Editor of the series and serves as an unpaid editorial board member of Annals of Palliative Medicine from Jul 2019 to Jun 2021. TLC served as the unpaid Guest Editor of the series. Both authors have no other conflicts of interest to declare.

Ethical Statement: The authors are accountable for all aspects of the work in ensuring that questions related to the accuracy or integrity of any part of the work are appropriately investigated and resolved.

Open Access Statement: This is an Open Access article distributed in accordance with the Creative Commons AttributionNonCommercial-NoDerivs 4.0 International License (CC BY-NC-ND 4.0), which permits the non-commercial replication and distribution of the article with the strict proviso that no changes or edits are made and the original work is properly cited (including links to both the formal publication through the relevant DOI and the license). See: https://creativecommons.org/licenses/by-ncnd/4.0\%.

\section{References}

1. Seymour J, Clark D, Winslow M. Pain and palliative care: the emergence of new specialties. J Pain Symptom Manage 2005;29:2-13.

2. Hui D, Kim YJ, Park JC, et al. Integration of oncology and palliative care: a systematic review. Oncologist 2015;20:77-83.

3. Temel JS, Greer JA, Muzikansky A, et al. Early palliative care for patients with metastatic non-small-cell lung cancer. N Engl J Med 2010;363:733-42.

4. Zimmermann C, Swami N, Krzyzanowska M, et al. Early palliative care for patients with advanced cancer: a cluster-randomised 
controlled trial. Lancet 2014;383:1721-30.

5. Abrahm JL. The oncologist's expanding role. Cancer 1999;85:1645-8, iii.

6. Abrahm JL. Integrating palliative care into comprehensive cancer care. J Natl Compr Canc Netw 2012;10:1192-8.

7. Lam TC, Tseng Y. Defining the radiation oncologist's role in palliative care and radiotherapy. Ann Palliat Med 2019;8:246-63.

8. Sham MK, Yang JC. Hospice care and pain management in Nam Long Hospital, Hong Kong. J Pain Symptom Manage 1997;13:189-90.

9. Chan KS. Two decades of palliative care. Hong Kong Med J 2002;8:465-6.

10. Yeung R, Wong KH, Yuen KK, et al. Clinical oncology and palliative medicine as a combined specialty--a unique model in Hong Kong. Ann Palliat Med 2015;4:132-4.

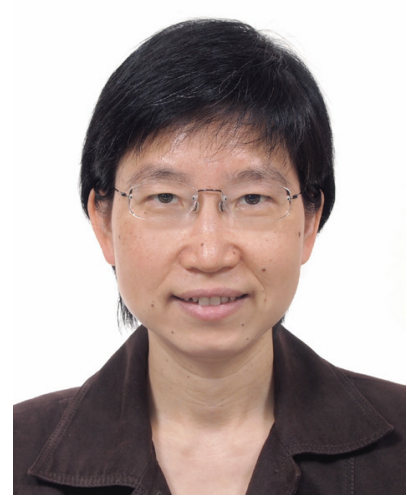

M. W. Rebecca Yeung

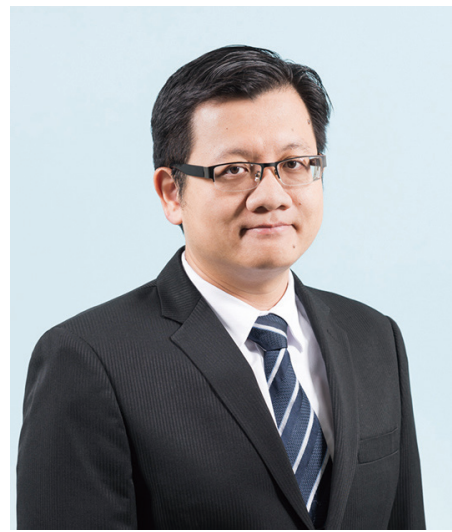

Tai-Chung Lam

M. W. Rebecca Yeung

Chief of Service, Department of Clinical Oncology, Pamela Youde Nethersole Eastern Hospital, Hong Kong, China.

(Email:yeungmwr@ha.org.hk)

Tai-Chung Lam

Clinical Assistant Professor, Department of Clinical Oncology, Li Ka Shing Faculty of Medicine, The University of Hong Kong, Hong Kong, China.

(Email:lamtc03@bku.hk)

Submitted Aug 04, 2020. Accepted for publication Aug 28, 2020. doi: 10.21037/apm-2018-ipco-11

View this article at: http://dx.doi.org/10.21037/apm-2018-ipco-11

Cite this article as: Yeung MWR, Lam TC. Integrating palliative medicine in oncology care: the Hong Kong experience. Ann Palliat Med 2020;9(6):4427-4429. doi: 10.21037/apm-2018-ipco-11 